\title{
The ultimate bluff: a case study of partygaming.com
}

\section{Des Laffey}

Kent Business School, University of Kent, Canterbury, UK

\section{Correspondence:}

D Laffey, Kent Business School, University of Kent, Canterbury CT2 7PE, UK.

Tel: + 44 (0)1227 827489;

Fax: + 44 (0)1227 761187;

E-mail: D.J.Laffey@kent.ac.uk

\begin{abstract}
June 2005 was to bring online gambling out of the shadows and into the spotlight. PartyGaming, a start-up formed in 1997, launched a flotation (Initial Public Offering) on the London Stock Exchange that valued the firm at $£ 4.64$ billion giving it a larger market capitalisation than British Airways. PartyGaming had become the dominant player in the booming online poker market with its PartyPoker brand having over 50\% market share. However, this float - as with Internet gambling in general - was not without controversy. While PartyGaming had an online gambling license from the tax haven of Gibraltar, nearly $90 \%$ of its revenue came from the United States, where the authorities viewed Internet gambling as illegal and threatened legal action. The complex operations of this truly global firm with bases in London, India, Gibraltar and Canada, the background of its founder Ruth Parasol in Internet pornography and the handling of its flotation also raised concerns from an ethical perspective, with some commentators questioning whether the float should have been allowed at all. These concerns were then confirmed as US legislation to curb online gambling was passed in September 2006, leading to PartyGaming's exit from the US market and an immediate fall of $58 \%$ in the share price. This case study analyses the entrepreneurs behind PartyGaming, its growth, the challenges it has faced, the ethical issues it poses and its future prospects. The case draws on theory from e-commerce, strategy and ethics.
\end{abstract}

Journal of Information Technology (2007) 22, 479-488. doi:10.1057/palgrave.jit.2000096

Published online 10 April 2007

Keywords: e-commerce; online gambling; poker; dot.coms

\section{Introduction: the dot.com casino}

It is usually agreed that casinos should, in the public interest, be inaccessible and expensive. And perhaps the same is true of Stock Exchanges (Keynes, 1936: 159).

$\mathrm{n}$ the 1990s, venture capitalists were prepared to gamble huge amounts on dot.com start-ups, even if they involved unproven business ideas. Booming stock markets created ideal conditions for such activity as it offered easy exit routes for investors via initial public offerings (IPO). Many dot.com shares would rapidly accelerate and the phenomenon of the 'day trader', whereby individuals would make short-term investments in hot shares, gave a further momentum to share prices. With the huge profits made by some venture capital investments for example Yahoo (Sequoia Capital) and eBay (Benchmark
Capital) - and some individual share traders, a 'herd mentality' developed and more money was ploughed into the dot.com dream.

However, in 2000, boom turned to bust as it became clear that the dot.com sector was overvalued and while some firms had a promising future, many did not. This initiated a sharp downturn, with venture capitalists and the financial markets becoming wary of dot.coms. The description by the famous economist John Maynard Keynes of the stock market as a 'casino' and of the short-term 'animal spirits' of capitalism had never seemed more apt (Keynes, 1936).

In an ironic twist, an online gambling firm, PartyGaming, would launch a 2005 IPO (known in the UK as a flotation) on the London Stock Exchange, valuing the firm at $£ 4.64$ billion in the biggest UK flotation for five years (Reuters, 2005). PartyGaming had grown through its dominance of the booming American online poker market where its PartyPoker brand had an estimated market share of over 
$50 \%$ and 2004 revenues of $\$ 553$ million (PartyGaming's reporting currency is US Dollars). With gross margins of over $60 \%$, PartyGaming appeared to be a prime candidate for a flotation.

However, a huge cloud hung over the flotation and the future of PartyGaming. Online gambling was viewed as illegal by the US Department of Justice who threatened legal action. These threats were discounted by the firm as it felt US legislation allowed its activities, but even if it did prove unlawful, its assets were outside US jurisdiction. Eyebrows were raised that the London Stock Exchange allowed such a company to join its ranks and that investment banks were prepared to manage and underwrite the float (Peston, 2005). This uncertainty led to the offer price being reduced but the float was still oversubscribed and the shares rose $11 \%$ on the first day of trading.

\section{The beginnings}

Ruth Parasol, who founded what would become PartyGaming, has long been a controversial figure. The daughter of a massage parlour owner in San Francisco, she was educated at the University of San Francisco and then Western State University in Fullerton, California where she studied Law. She co-founded a telephone sex line business before investing with her father in The Internet Entertainment Group (IEG), a notorious online pornography business. The IEG generated large profits before it ended up collapsing amidst legal challenges and financial mismanagement. However, Parasol had managed to cash in her investment before the problems emerged, and would use the money to invest in another industry which was showing promising growth on the Internet, gambling (Eichenwald, 2005).

\section{What is gambling?}

Gambling involves participants risking money on the outcome of an unknown event for gain. Its traditional products can be seen on a spectrum from pure games of chance - such as slot machines, bingo, numerous card games, roulette and lotteries - to activities which can involve judgment, such as the card game poker and betting on events such as the outcome of a sports event. As the growth of Parasol's activities excluded betting on events, their mechanics will not be covered.

How the gambling operator generates revenue depends on the particular product on offer. With games of chance such as lotteries and bingo, the amount paid out will be a certain percentage of the amount staked after covering costs and a profit margin. With games such as roulette and slot machines, heavy short-term payouts may be made but over time the probabilities in the games ensure a chouse advantage' with guaranteed profit margins.

\section{The mechanics of poker}

Poker comes in many variants but all types involve players betting against each other on who has the best combination, or 'hand', of cards. In all forms of poker at least some of these cards are unknown to other players, a fact that has given poker its glamour and aura of mystery.

Betting takes place in 'rounds' after which new cards are dealt, or made available. When the betting starts if players believe they have a chance of winning they have the option to 'call' the bet, or stay in the game by equalling the amount bet, or 'raising', namely, increasing, the amount bet. If a player does not think their hand will win, they have the option to 'fold', or withdraw from the game, losing the amount they have bet. If all but one player folds, the remaining player wins the game, without having to reveal their hand, which makes 'bluffing', pretending to have better hand than the player in fact holds, a viable option.

If after the betting has finished there is more than one remaining player, the player with the best hand wins the game and takes the amount bet, known as 'the pot'. In the case of a poker tournament, where players compete on a knockout basis until there is only one player left, there is a prize for the winner and runners up.

The operator provides the environment for this to happen in terms of a venue with poker tables and dealers, and obtains revenue through taking a percentage of the pot, termed 'the rake', or entrance fees.

\section{The US gambling market: regulation and size}

Ethical concerns about gambling, with its potential for addiction and criminal involvement, have resulted in its prohibition in many countries or alternatively in restricted provision, for example with state-controlled monopolies. Legalisation has often been merely a realisation that gambling cannot be stopped and that regulation prevents its worst excesses, maintains standards of fairness, and enables gambling to be taxed/some of the proceeds to be used for good causes. What gambling products are available, and in what venues, will vary according to the jurisdiction.

In the market that Parasol would target - the United States - gambling legislation is set at the state rather than the national level. Eadington (1999) explains how the business of gambling in the United States was at its lowpoint in the early 1960s. Legal provision outside liberal Nevada, which legalised gambling in 1931, was restricted to bingo controlled by voluntary organisations, limited horse racing betting at the racetrack only in some states and card games of skill in California. Indeed, '[e]ven social gambling, like a poker game around the kitchen table, was illegal in many states' (1999, p. 174). The casinos of Nevada, although highly profitable, were seen by many as centres of criminality that caused major social harm.

However, in the 1970s, Nevada allowed publicly traded corporations to obtain gambling licenses that enabled the entry of large firms and led the industry to lose its association with organised crime. This made gambling more acceptable and in turn encouraged further legislation that led to authorised casinos in other states, the hugely significant introduction of Native American Casinos, and also Riverboat casinos. Slot machines and other forms of electronic gaming devices were allowed outside of casinos in the 1980s which saw their growth into bars and race tracks (Eadington, 1999; National Gambling Impact Study Commission, 1999).

The net result of this liberalisation was that by 1999, 31 states either had, or had approved, some form of casino gambling (American Gaming Association, 2000) and some forms of gambling were available in all states except Utah 
and Hawaii (National Gambling Impact Study Commission, 1999). The growth this relaxation led to is shown by the growth in gambling revenues (after pay outs) from $\$ 17.3$ billion in 1982 to nearly $\$ 51$ billion in 1997, with the leading category being casinos (Eadington, 1999).

However, entry into the casino industry was difficult, as a result of regulatory controls, as for example in Atlantic City or the rights offered to the Native American Casinos, and because of the economies of scale, facilities and strong brands that the corporate giants had developed. The huge investment and risk involved in entering the casino market was illustrated by the capital expenditures of MGM Mirage, the industry giant, for the years 1999, 2000 and 2001 of $\$ 375$ million, \$336 million and \$328 million, respectively (MGM Mirage, 2002: 27).

\section{Gambling on the Internet}

The growth of the Web seemed to offer a means of entering the gambling market with relatively low investment. During the 1990s the number of Americans adults with access to the Internet (from any location; home, work, etc.) grew from under 9\% in 1995 to 30\% in 1997 (ClickZ, 2001). The Internet was also becoming a commercial opportunity as an estimated $\$ 2.4$ billion was spent by American consumers online in 1997 (Clark and Miles, 1997).

Gambling also appeared to be the perfect industry for the Internet as it involved the transfer of information rather than the delivery of physical products with its associated problems. This led to the first online casinos appearing with Microgaming, a software provider to the industry, launching the first 'fully operational online casino' in 1994 (Microgaming, 2005).

However, the United States Department of Justice interpreted the Wire Communications Act of 1961, which banned interstate telephone sports betting, as applying to online gambling. This meant that emerging online gambling firms would base themselves in offshore locations such as the Caribbean that were happy to offer gambling licenses in an effort to boost their local economies.

\section{Start-up}

This potential market led to Parasol setting up the Starluck Casino website in September 1997 offering games of chance using software licensed from a third party. The company obtained a regulatory license from the Dominican Republic where it based its management and website. The company then established itself in the online gambling world through publicity and an active marketing campaign. It was named as one of the top five websites by the gambling portal Gambling.com and received coverage in gambling magazines such as Casino Player and websites such as Prescription and Virtual Vegas. Visitors were attracted using the affiliate marketing methods introduced by Amazon, whereby other websites would place banner adverts for Starluck Casino on their website and receive commission on the amount a user then gambled. By December 1998, Starluck Casino stated on its website that it had paid out over $\$ 500,000$ in commission and that some affiliate websites were receiving $\$ 15,000$ per month (Starluck Casino, 1998).
The online gambling industry as a whole was growing rapidly in the 1990s, although estimates were difficult to make as it was unregulated and global in nature. The National Gambling Impact Study Commission's report (1999) included various forecasts which each estimated that revenues and numbers of users had doubled between 1997 and 1998, with an upper estimate of $\$ 919.1$ million revenues and 14 million users in 1998. However, barriers to entry in the online gambling market were extremely low as standard software could be purchased off the shelf and licenses could be obtained relatively easily. But if barriers to entry were low, gaining the trust of consumers was rather more of a challenge, as unlike sports betting, where outcomes were public knowledge, outcomes in casinos were more open to manipulation by the operator. This would lead to the Interactive Gaming Council emerging as a trade body in 1996 to set standards and also to the growth of specialised firms offering audit services to verify fairness.

\section{Online poker - playing your cards right}

In 1997, Parasol would set up iGlobalMedia which became a vehicle for a range of gambling services, offering its own gambling sites (including Starluck Casino), portals to gain advertising revenues, marketing services and also sold gambling software to other online casinos (iGlobalMedia, 2000).

In 1998 Parasol, via a friend, met Anurag Dikshit, a 25year-old Indian computer specialist, who she persuaded to develop software for the website to enable better service. A recognition of Dikshit's abilities was the $42 \%$ stake he acquired in the new venture in 1999. Dikshit then hired a friend from his student days at the Indian Institute of Technology, Vikrant Bhargava, who would become Marketing Director in 2000. It was then the ability of this expanded team to grasp the potential of the emerging online poker market in 2001-2002 that would enable iGlobalMedia, renamed as PartyGaming in 2005, to eventually become a member of the UK's top one hundred companies (Pratley, 2005b) (For consistency this case will refer to the company as PartyGaming).

As illustrated in Figure 1, organised poker is played in only 16 American states that include 11 casino states and five states where the game is played in card rooms. Card rooms are venues that are only allowed to offer games of skill between individual players, that is, no games are allowed against the house (for example, slot machines). The Californian card rooms are by far the dominant poker venue in the United States generating at least half of all poker revenues (American Gaming Association, 2005).

Figure 1 clearly shows the large distances many Americans have to travel to play poker in land-based venues. Poker had not shared in the gambling boom of the 1980s and 1990s and revenue had been on a downward trend (American Gaming Association, 2004). The reasons given for this were a lack of interest from players and poker's lower profitability compared to other casino products. While an individual can play a slot machine quickly, poker requires coordinating the demand of enough players, licensed dealers and sufficient space for poker tables. In California competition from Native American Casinos, which could offer slot machines and the more 


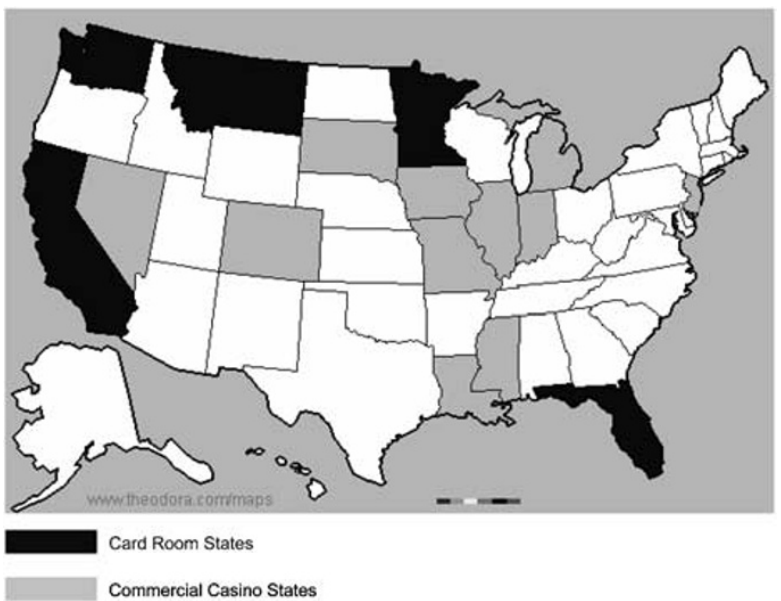

Figure 1 US States which allow poker (Source: American Gaming Association, 2004). Developed using a map courtesy of www.theodora.com/maps, used with permission.

profitable blackjack, had led to a halving of the number of poker tables from 1997 to 2003 and profit margins of less than $10 \%$ (CNN, 2003). A measure of its relatively low significance was the total absence of the word 'poker' from the American Gaming Association (the trade body for the industry) Annual Reviews for the period 1999-2002.

Online poker had emerged in the 1990s with the first site being launched by Planet Poker in 1998. By 2000 poker was showing promising growth with the early market leader being the 1999 start-up Paradise Poker. The online game was an attractive offering for US citizens who could now play in their own home. For beginners or those with less confidence, the online game also offered the opportunity to play without money, and then play for small stakes in a less intimidating environment than a land-based poker table. Online poker also offered quick thinkers the ability to play at simultaneous tables, something obviously not possible in poker rooms.

PartyGaming quickly saw the potential the online game offered, to quote Bhargava:

In early 2000 everybody was talking about Paradise Poker and we saw them and thought 'they're making money, so can we' (Pratley, 2005a: 1).

Bhargava thought that most of the available websites were not easy to use and with Dikshit's technological prowess market entry would be possible. This market entry would be launched via a new brand, PartyPoker, from the Native American Kahnawake Province in Canada, from which a gambling license was obtained in 2001.

The need for liquidity

The challenge lay, however, in determining how to attract sufficient liquidity to the new poker operation. Poker is a game between players, rather than against the house, and so players are attracted by the presence of other players, providing an advantage to existing sites and a barrier to new entrants. In simple terms, if someone enters a poker site and is unable to participate they are less likely to return (this is the network externalities phenomenon identified by Shapiro and Varian (1998)). Financial success in this field would also require liquidity as revenue was obtained as a small percentage of the amount staked on each game. Moreover, a new player had to establish brand recognition and credibility quickly as the reputation of online poker had received a serious blow in 2000 with the collapse of a new player Pokerspot.com, with loss of client funds.

To gain brand recognition, the famous Las Vegas-based professional Mike Sexton was recruited to be the public face of PartyPoker. Sexton came up with a masterstroke; a Poker tournament called the PartyPoker Million where the prize for the winner would be $\$ 1$ million (Shulman, 2004). There was nothing particularly innovative about tournaments as these were available in land-based venues and were also being offered in the online market. However, no other online operator offered a prize of anywhere near this amount and the World Series of Poker in Las Vegas (the largest poker tournament in the world), which offered a prize of \$1.5 million in 2001 charged standard entry fees of $\$ 10,000$. PartyPoker would enable mass participation with entry fees starting at just $\$ 22$ for online players, providing the opportunity for anyone to win a fortune (Pratley, 2005a; PartyPoker.com, 2006).

In another major innovation, the PartyPoker team decided to play the final round live to overcome doubts as to whether the $\$ 1$ million first prize money had ever been paid out. A series of mini tournaments were played online and the final 100 players plus their partners were then invited on an all expenses paid week long cruise with $\$ 500$ spending money where the final round would be played. In an effort to recoup the costs of the tournament players could also buy-in to the final, with 39 doing so at a cost of $\$ 8000$ each. In March 2002 Kathy Liebert a well-known professional player, won the first prize in a thrilling final. Liebert was the first ever woman to win a prize of this size helping to boost the appeal to female players, while an online qualifier came second winning a $\$ 93,600$ consolation prize. While PartyPoker lost $\$ 500,000$ on the event, substantial media coverage was generated with the Travel Channel showing the whole event a number of times (Johnson, 2002).

This attention attracted further players to the site and by the end of 2002 PartyPoker had 6000 active poker players and an estimated $20 \%$ of the market. In this year, $\$ 9.7$ million revenue came from poker which represented about $30 \%$ of overall group revenue. At the end of 2002, a further key decision was made, to strengthen the Indian connection and set up a subsidiary in Hyderabad, which would use local low cost expertise to handle IT and customer support (PartyGaming, 2005).

The lucky streak

The year 2003 was the year that poker would become a phenomenon in the United States. Entrepreneurs Steve Lipscomb and Lyle Berman came up with an idea to turn poker into a spectator sport, with coverage along the lines of Golf and Grand Prix. Until then the World Series of Poker had been shown on television but there was no regular coverage of poker throughout the year. This would change with the introduction of the World Poker Tour, 
which consisted of a series of land-based poker tournaments that were covered by the Travel Channel. The use of under the table cameras provided a unique and gripping insight into the bluffing and psychology of poker and produced record viewing figures (Brady, 2005). What was even better for PartyPoker was that Mike Sexton was the official host of the World Poker Tour and provided expert commentary. This closeness to the Travel Channel then enabled PartyPoker to 'flood' the World Poker Tour coverage with advertising that starred Sexton. While Sexton's mixing of roles had clear conflicts of interest, the success of the World Poker Tour enabled PartyPoker to assume market leadership by the middle of 2003 with an estimated 50\% market share (Pratley, 2005b).

Moreover, PartyPoker had gained control of a booming market as poker was becoming a craze in the United States. The online operators copied the idea of offering 'satellite' tournaments from land-based venues, in which players would pay a relatively low entry fee for the potential prize of entry into the World Series of Poker. In what could have been a Hollywood script, a novice player would pay just $\$ 40$ to enter an online tournament, qualify for the World Series of Poker which had over 800 finalists including top professionals and triumph with the $\$ 2.5$ million first prize. While the aptly (and amazingly!) named Chris Moneymaker qualified via the rival PokerStars website, this was amazing publicity for the whole industry fuelling further growth. Celebrities would become part of the poker frenzy with Nicole Kidman and Ben Affleck playing in a televised game which drew in an audience of 13 million (Roy, 2005).

\section{The marketing blitz}

PartyPoker rode the poker boom, through a mix of marketing methods which drew in existing poker players and also brought in people new to poker (PartyGaming, 2005). These methods included the following:

\section{Advertising}

Along with TV an aggressive advertising campaign was carried out which included traditional media as well as online methods. Sponsorship of television programmes, direct mail campaigns, adverts on national and local radio stations, and adverts in the print media were all used to attract people to the site. In the online area adverts were placed on major websites, and keywords were purchased on search engines such as Google and Yahoo. In total, this led advertising expenditure to increase from $\$ 1.6$ million in 2002 to $\$ 31.6$ million in 2004 .

\section{Affiliates}

In the online sphere, the affiliate methods started by Starluck Casino made a huge contribution. In 2004 the company had over 4000 affiliates who generated $\$ 152.6$ million of poker revenues, $28 \%$ of the total, at a cost of \$44.4 million.

\section{Acquisition fees}

Bonuses were offered to new players, and referral payments when players introduced a new customer to PartyPoker. To retain players, bonuses were also awarded to existing players and a loyalty scheme introduced in November 2004.
Skins

PartyPoker also obtained revenue through offering its poker platform (and liquidity) to other websites with a revenue split between the parties. Skins generated $3 \%$ of poker revenue in 2004 .

\section{Tournaments}

The PartyPoker Million became an annual event, and in an effort to compete against rival tournaments, the prizes grew to $\$ 7$ million for PartyPoker Million V in 2005. In addition to this once a year event, other regular online tournaments were introduced which grew to a $\$ 1$ million tournament once a month and weekly tournaments with $\$ 200,000$ and $\$ 350,000$ prizes. Liquidity is crucial for tournaments' viability as players' buy-in fees fund the prize pool, so that more players enable bigger prizes to be offered. Tournaments were also crucial for publicity and revenue with $28 \%$ of PartyGaming's poker revenue coming from entry fees in 2004.

The booming demand for poker and PartyPoker's liquidity and marketing enabled it to grow its number of active players hugely as shown in Figure 2.

Land-based poker venues also experienced sharp increases in demand, but geographic limits on demand and capacity constraints limited the ability of the traditional venues to benefit as much as the online version. Between 2003 and 2004, poker revenue in the Casino States of New Jersey and Nevada (the only states which track poker revenue) increased by over $44 \%$ to over $\$ 144$ million, while in the Card Room States revenue (which includes other card games) increased by nearly $20 \%$ to just over $\$ 1$ billion. However, in the Card Room States, the number of poker venues increased by just over $6 \%$, while the number of venues in California actually fell (American Gaming Association, 2005).

In sharp contrast, the technology infrastructure of PartyPoker enabled a business with amazing scalability. To quote from the flotation prospectus (PartyGaming, 2005: 93), 'the number of active real money poker players' increased 'from approximately 6,000 in December 2002 to 324,000 in December 2004', which enabled revenues to grow from \$9.7 million in 2002 to \$123.4 million in 2003 and \$553 million in 2004. The technology infrastructure enabled 70,000 simultaneous poker players on a regular basis in 2004 , and at its peak this increased to 80,000 - which for the

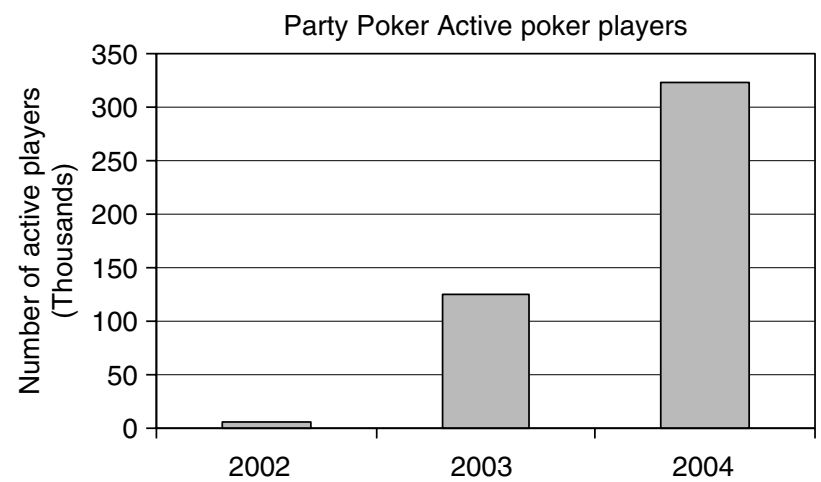

Figure 2 Growth in number of active PartyPoker customers 2002-2004 (Source: Developed using data from PartyGaming, 2005) 
Table 1 Comparison of capital expenditure for PartyGaming and MGM Mirage 2002-2004

\begin{tabular}{llll}
\hline & 2002 & 2003 & 2004 \\
\hline MGM Mirage & $\$ 702$ & $\$ 550$ & $\$ 300$ \\
PartyGaming & $\$ 0.6$ & $\$ 6.1$ & $\$ 11.9$ \\
\hline
\end{tabular}

Millions of Dollars.

Source: MGM Mirage (2005), PartyGaming (2005).

most popular variant of poker, Texas Hold Em, is the equivalent of approximately 40 times the capacity of the largest poker venue in the world, the 243 table Commerce Casino in Los Angeles.

In the area of tournament prizes online poker was at a huge advantage given its ability to connect tens of thousands of players. The regular prizes on offer online just could not be matched by poker rooms. To place this in context the Commerce Casino advertised on its website in May 2006 a weekly tournament with a typical prize pool of $\$ 17,000$, about $5 \%$ of that on offer in PartyPoker's equivalent.

This increase in capacity was also done with minimal levels of capital expenditure, as shown by Table 1 that compares the capital expenditure of PartyGaming and the casino giant, MGM Mirage.

\section{Financial performance}

Costs were further minimised by the location of PartyGaming's labour intensive support functions in low cost India (with $85 \%$ of its 1100 staff being located there in 2005). This effective cost control enabled operating margins of over $60 \%$ in 2003 and 2004 as shown in Figure 3. These margins dropped in 2005 with flotation-related costs and a settlement with its major skin, Empire - over $\$ 230$ million in one-off costs - accounting for the declining performance (PartyGaming, 2005, 2006).

Much of this growth had come from poker, with its contribution to group revenue increasing from $30 \%$ in 2002 to $88 \%$ in 2005 . The company's location in the tax haven of Gibraltar additionally enabled it to pay less than $6 \%$ tax on its operating profit, \$21.6 million in 2004 .

\section{Challenges}

\section{Security}

In 2004 there were news reports that many gambling websites were facing extortion threats from criminal gangs based in Eastern Europe. Unless payments were made denial-of-service (DOS) attacks would be launched, in which a website is overloaded with requests for data, causing it to crash. With the complete dependence of revenue on the website this was a particular threat to PartyGaming, and its site was to be brought down such attacks in 2003 and 2004 (PartyGaming, 2005).

Trust

Online gambling already faced the problem of gaining the trust of users. The use of independent auditing systems
PartyGaming Financial Performance 2002-2005

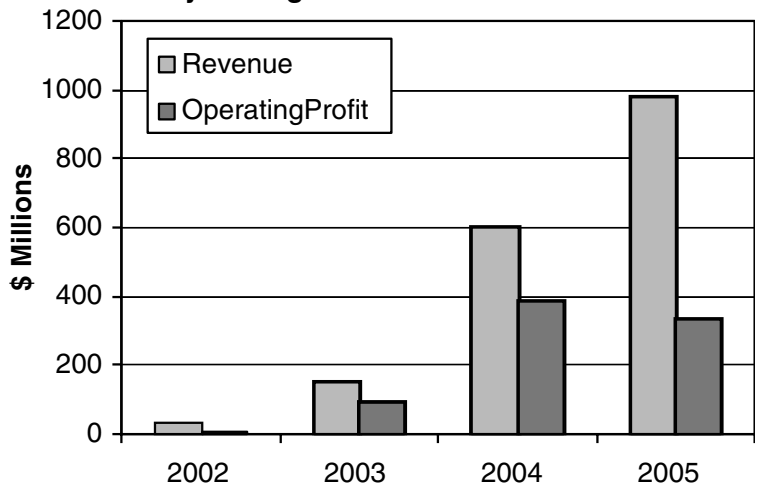

Figure 3 PartyGaming financial performance 2002-2005 (Source: Developed using data from PartyGaming, 2005 and PartyGaming, 2006).

could ensure games were not being manipulated and publicity generated through the media and high profile advertising helped to build the PartyGaming brand. In poker the use of unfair means by others, both by the use of technology and of manual methods, needs to be prevented, given that participants are playing against other people.

One such technological threat to fair poker was the use of bots - software that had optimal poker strategies masquerading as human players. These were reported in the media as being used on poker websites (Waller, 2005). However, while bots could only operate in the online world, data captured on a player's history offered an opportunity to identify the use of such methods.

Another fear of online poker players was that games could be manipulated by means of other players colluding, for example trying to increase the amount staked on a table so a collaborator could benefit. Here too, data available could be used to find patterns of recurring behaviour and then used to ban offenders (PartyGaming, 2005).

\section{Market saturation}

The PartyGaming prospectus estimated that the online poker market would grow from a value of $\$ 1$ billion in 2004 to $\$ 6.4$ billion in 2009 , as players switched from land-based venues and new players were also brought to online poker. It appeared that PartyPoker with its liquidity and resources was positioned for strong growth. However, those who doubted PartyGaming's float and valuation argued that the rapid growth in online poker would have to level off at some point and that competition would hit margins (Peston, 2005). Intense marketing activity from the more than 200 online poker websites, which typically offered generous customer acquisition incentives, increased costs for all firms as they strove to retain customers.

\section{The dark cloud}

The belief of the United States Department of Justice was that gambling activity took place in the jurisdiction of the customer and that the Wire Communications Act prohibited such activity. PartyGaming, on the other hand, argued that their activities were legal as gambling took place in the jurisdiction of the server. Furthermore, PartyGaming argued that the Wire Communications Act only applied 
to sports betting, citing case law from 2002 (PartyGaming, 2005). But irrespective of the legal situation they were not going to be deterred by US threats. A quote from the flotation prospectus makes this clear (p. 14)

PartyGaming and its directors rely on the apparent unwillingness or inability of regulators generally to bring actions against businesses with no physical presence in the country concerned.

This did not prevent attempts to prohibit its activities by means of legislation, however. Angered by the rise of online gambling Senator Jon Kyl of Arizona and other politicians attempted to introduce various forms of legislation to make online gambling illegal, attempts that eventually succeeded in September 2006 (covered below).

In a further attempt to squeeze online gambling, the US authorities had been applying pressure to those supplying payment processing. Along with problems such as disputed online payments this led to US credit card issuers such as Citibank and American Express refusing to allow gambling payments through their cards. This pressure also led to PayPal, the e-wallet firm owned by eBay, to withdraw service for gambling. In response, PartyGaming successfully developed their own e-wallet system that enabled customers to pay and withdraw funds.

Similar pressures emerged in advertising as the Department of Justice wrote to firms, who were 'urged' not to accept advertising from online gambling firms, with Yahoo and Infinity Broadcasting among those cooperating. In April 2004 over \$2 million of PartyGaming's money for prepaid advertising, was seized from the offices of Discovery, owners of the Travel Channel, by US marshals working for the Department of Justice. However, some media firms were still happy to take advertising. In addition to this, to get around the crackdown an educational website, PartyPoker.net, which taught people how to play poker was launched and promoted thus enabling awareness of the PartyPoker brand to be generated.

\section{Every cloud has a silver lining....}

Ironically, the US situation protected PartyGaming's market dominance as it created a powerful entry barrier to US firms. The casinos and major Internet firms could use their powerful brands and financial resources to offer online gambling products, but could not accept US consumers as this would lead to action by the authorities. MGM Mirage had launched a poker website based in the Isle of Man, but the site did not cater for US citizens and thus failed to attract a critical mass of players.

\section{Royal flush - the flotation}

In preparation for its flotation PartyGaming brought in an experienced management team. These included a new Chief Executive Richard Segal, previously the CEO of Odeon, the cinema chain, and well known in the investment community of the City of London.

Eyebrows were raised about the float on London's senior market, mainly concerning the issue of legality of the company's operations. Other issues were raised vis-a-vis the corporate governance of the firm and the motivations behind its flotation. Its (non-executive) chairman Michael Jackson was already chairman of another firm in the FTSE 100 that contravened the Higgs Code on Corporate Governance. Moreover, Jackson and the four other nonexecutive directors all received payments with the flotation, some of which they each invested in shares at the offer price - a situation that appeared to break the Higgs Code which stated that non-executive directors should be independent, and not be paid additional remuneration or normally take part in share schemes (Wild and Day, 2005).

Further doubts were raised about why the company was even floating. The float was not to raise capital as PartyGaming was hugely profitable, rather the owners were using this opportunity to harvest some of their investment. Some questioned their motives, wondering why such a cash cow should go public and attract such attention to itself.

If PartyGaming were as good as it looks, Dikshit et al. could take out hundreds of millions of dollars in dividends every year while retaining all the equity in it. Thus my fear is that their share sale represents a lack of confidence in its future (Peston, 2005: 1).

In spite of these doubts PartyGaming's float was successful and it raised over $£ 900$ million giving a valuation of $£ 4.64$ billion. The shares rose sharply in the first 2 months peaking at $50 \%$ above the flotation price as the stock market warmed to the company and online gambling.

However, a trading update in September 2005 warned that growth was slowing and resulted in a fall of over $30 \%$ in the share price demonstrating just how easily sentiment could turn against online gambling firms. The share price, however, picked up again with more positive trading news and was 10\% above its flotation offer price on 23 May 2006.

\section{The ambush}

The combination of dot.com, Internet gambling and the associated legal fears would always make this a volatile investment. In 2006 it appeared as though attempts to introduce laws to prohibit online gambling would fail, as had been the case on many previous occasions. The Unlawful Internet Gambling Enforcement Act which would make it illegal for banks and credit card companies to transmit funds to 'unlawful Internet gambling' operations passed through the House of Representatives in March 2006, but it was thought that this legislation would not get through the Senate.

However, in August and September of 2006, executives of UK listed online gambling firms were arrested while at US airports, an action that was seen as the start of an aggressive campaign against online gambling. Then, in a dramatic move, The Unlawful Internet Gambling Enforcement Act was added on to an unrelated piece of legislation, the Safe Port Act, which had strong cross party support in the Senate. The impact of the Act was immediate as PartyGaming and other firms listed on the London Stock Exchange made announcements that they would no longer offer services to US customers. This inevitably took a heavy toll on their share prices and on the first day of subsequent trading PartyGaming lost 58\% of its value. Moreover, a loan 
facility for $\$ 500$ million now had to be renegotiated as a clause had been inserted to cover the possibility of US legislation.

There were protests against the legislation with claims that it was unfair as limited online gambling provision within the United States by US regulated firms were allowed to continue, in the areas of horseracing, fantasy sports, lotteries and remote access to some Nevada casinos. There was also speculation that a case would be brought against the United States at the World Trade Organisation, where a case had already been lost against Antigua in 2006 over sports betting. However, it was doubtful whether such action would have any impact and a crushing blow had been dealt against the online gambling firms from the London Stock Market.

In contrast some of the smaller, privately held gambling firms stated that they would continue to serve the US market. As the majority of funds used for online gambling by US citizens were not transferred by credit card (such attempts were generally rejected), but by e-wallets, it seems likely that online gambling will continue. For those determined enough, too, funds could be transferred to a foreign bank that could then be used to fund gambling activity. And finally, the Act also does not require the monitoring of the 40 billion checks which are written in the United States every year (Nelson Rose, 2006).

\section{The uncertain future}

The need for new markets

Aware of its dependence on the US market, PartyGaming had been aiming to develop its business in other key markets, a point it stressed in its flotation prospectus (PartyGaming, 2005). With the US legislation of September 2006 this now became critical for the future of the company. In $2004,13 \%$ of its revenue was from outside the United States, with 5\% from Canada, 5\% from Europe and 3\% from the rest of the world. This would grow to $16 \%$ in 2005 . The non-US markets represented considerable opportunities for PartyGaming, given that non-US revenues represented 53\% of global gambling revenues in 2005 (PartyGaming, 2006). However, such overseas expansion would present problems of local knowledge and established competitors. As an example Ladbrokes, the leading UK bookmaker, claims to be the busiest European poker website having wide brand recognition, and hosting tournaments with million pound plus prizes (Ladbrokes Poker, 2006).

\section{Growth via the Party brand}

PartyGaming looked to utilise the strength of its brand by renaming its Casino and Bingo products under the Party brand. Further products were introduced under this brand umbrella with backgammon, a popular game in the Middle East, being launched in 2006. As a further method of strengthening these products and to enable cross selling, a 'shared purse' was introduced that enabled customers to use the same funds across the different gambling products offered by the Party brand. PartyGaming also sought to make acquisitions in related gambling markets with the August 2006 purchase of Gamebookers (an online sports betting operator based in Bulgaria) for 102 million Euros, in an attempt to diversify its business. To fund possible further acquisitions and in reaction to the harsher financial environment, a dividend payment of $\$ 115$ million was cancelled in October 2006.

\section{The ultimate bluff}

PartyGaming, and investors in the firm, had gambled that the US would not legislate against online gambling. In September 2006 their bluff was called. Ironically, in the same way that regulation had prevented US firms from entering this market and had enabled this firm to emerge, its status and responsibilities as a regulated public company now forced it to exit the US market.

In its place privately owned, and no doubt increasingly secretive, firms would continue to operate, as PartyGaming's past successes had shown clearly the enormous potential for profit in online gambling in the US market.

The online gambling genie was out of the bottle, and the desire of American citizens to gamble online would not go away. The story of Aaron Kanter in 2005 demonstrates the lure of online poker. He paid $\$ 50$ to compete for a place at the World Series of Poker via a tournament at PartyPoker, qualified and went on to finish in fourth place winning a prize of $\$ 2$ million. The dot.com casino will be open as long as there are people wishing to live out the gambler's dream.

\section{Methodology and teaching note}

\section{Methodology}

PartyGaming, a start-up formed in 1997, launched an IPO (flotation) on the London Stock Exchange in 2005 that valued the firm at $£ 4.64$ billion giving it a larger market capitalisation than British Airways. PartyGaming had become the dominant player in the booming online poker market with its PartyPoker brand having over $50 \%$ market share. However, nearly $90 \%$ of its revenue came from the United States, where the authorities viewed Internet gambling as illegal and threatened legal action.

The complex operations of this truly global firm with bases in London, India, Gibraltar and Canada, the background of its founder Ruth Parasol in Internet pornography and the handling of its flotation also raised concerns from an ethical perspective, with some commentators questioning whether the float should have been allowed at all. These concerns were then confirmed as US legislation to curb online gambling was passed in September 2006, leading to PartyGaming's exit from the US market and an immediate fall of $58 \%$ in the share price.

The growth of PartyGaming thus appeared to offer considerable potential as a classroom case study as initial examination showed it covered key issues in the area of ecommerce, the growth of a new venture, entering an industry with high entry barriers, product innovation via the Internet, coping with growth and the issue of regulation.

The case also raises ethical issues about online gambling that have also been usefully explored in classroom discussion. The breakdown of national regulation in the area of gambling markets brought on through the Internet 
and the subsequent legislation from the United States also makes this a timely case.

\section{Case information}

The case was developed using information available in the public domain, which included:

- PartyGaming's Flotation Prospectus published in 2005.

- PartyGaming's Annual Report published in 2006.

- Various press releases from the company.

- Reports from US Government bodies and the American Gaming Association, the industry trade body in the United States.

- Reports from newspapers, business magazines, websites and specialist gambling publications.

- Relevant academic publications in the areas of ecommerce, gambling and other areas.

\section{Case organisation and writing}

The case was organised to analyse how PartyGaming had emerged in such a highly regulated industry. It was thought that the localised nature of gambling laws made it essential that particular focus was given to the legal status and organisation of US gambling, the market which was targeted. Attention was also given to the game of poker in its traditional format and its restricted geographical availability in the US. Consideration was given here to the way PartyGaming capitalised on the early growth in the online poker market and through shrewd marketing and luck became the dominant force in the TV-fuelled poker craze that would grip the US from 2003 onwards.

A first version of the case was written by the author and then used with MBA students, from many nationalities, on an Information Systems MBA module for test purposes. This was a major success and provoked much debate in a lively, though good-natured manner. Use of the case and student feedback led to some revisions of the case, with further background added on the US gambling industry, clarification on the legal situation with the US and material added on the problems of managing growth that PartyGaming has faced.

The case was used twice more; on a Strategy MBA module, which covered New Venture Creation, and on an Entrepreneurship MBA elective. Students commented on how much they enjoyed it and the way it integrated several modules they had covered during their studies.

\section{Audience and uses}

This case has been used on MBA modules in entrepreneurship, e-commerce and strategy. The case illustrates the ability of the Internet to facilitate innovative new ventures that can challenge oligopolistic, heavily regulated industries. The case also highlights ethical issues in e-commerce with the US legislation in September 2006 that curbed online gambling making this a highly topical case.

\section{Essential background to addiction and social issues regarding} gambling

Clearly any form of gambling carries an inherent risk. For some the risk turns into addiction with serious consequences for themselves and their families.
Below are some useful sources from the United States and United Kingdom on gambling addiction in general, and on specific problems identified as a result of the emergence of online gambling.

\section{United States coverage}

BBC News. (2002) Internet gambling breeds addiction [WWW Document] http://news.bbc.co.uk/1/hi/health/ 1872731.stm, (accessed 9th October 2006)

BBC News. (2006) Online poker's grip on US youth [WWW Document] http://news.bbc.co.uk/1/hi/programmes/ crossing_continents/4806660.stm (accessed 9th October 2006)

National Council on Problem Gambling. (2001) Fact sheet in the United States on problem gambling [WWW Document] http://www.ncpgambling.org/media/pdf/ eapa_flyer.pdf (accessed 9th October 2006)

National Council on Problem Gambling. (2006) Statement on Internet Gambling by National Council on Problem Gambling [WWW Document] http://www.ncpgambling. org/media/pdf/igambling_statement.pdf (accessed 9th October 2006)

\section{United Kingdom coverage}

Griffiths, M. (2001) Brief Research Report: Internet Gambling: Preliminary Results of the First U.K. Prevalence Study, The Electronic Journal of Gambling Issues, Issue 5 [WWW Document] http://www.camh.net/egambling/ issue5/research/griffiths_article.html (accessed 9th October 2006). This paper, though from 2001 , looks at the results on a MORI survey on the prevalence of Internet gambling http://www.gamcare.org.uk (accessed 9th October 2006).

GamCare is a UK charity that provides information and advice on the social aspects of gambling. Gamcare offer a certification programme for operators who meet certain standards, one of whom is PartyGaming, in the following areas:

'Age verification systems, Customer led controls for spend and session play, Self-exclusion options, Reality checks within games screen, Social responsibility content and sources of help, Customer service training'. (http:// www.gamcare.org.uk/site.builder/Cert.html)

GamCare also offer a range of publications on gambling. Their 'Care Services' 2005 Report gives a range of data on problem gambling in the UK.

Further Teaching Notes are available to bona fide faculty directly from the author.

\section{References}

American Gaming Association (2000). State of the States, The AGA Survey of Casino Entertainment [WWW document] http://www.americangaming.org/ assets/files/AGA_SOS_2000.PDF(accessed 9th October 2006).

American Gaming Association (2004). State of the States, The AGA Survey of Casino Entertainment [WWW document] http://www.americangaming.org/ assets/files/2004_Survey_for_Web.pdf(accessed 9th October 2006).

American Gaming Association (2005). State of the States, The AGA Survey of Casino Entertainment [WWW document] http://www.americangaming.org/ assets/files/uploads/2005_State_of_the_States.pdf(accessed 9th October 2006).

Brady, D. (2005). TV poker's rising stakes [WWW document] http://www. businessweek.com/bwdaily/dnflash/mar2005/nf20050310_6684_db016.htm (accessed 9th October 2006). 
Peston, R. (2005). City comment: PartyGaming is far too good to be floated [WWW document] http://www.telegraph.co.uk/money/main.jhtml?xml = $/$ money/2005/06/19/ccom19.xml\&menuId $=242 \&$ sSheet $=/$ money $/ 2005 / 06 /$ 19/ixfrontcity.html(accessed 9th October 2006).

Pratley, N. (2005a). The poker face Vikrant Bhargava, marketing director of PartyGaming [WWW document] http://business.guardian.co.uk/story/ 0,1441390,00.html(accessed 9th October 2006).

Pratley, N. (2005b). The porn princess, the Indian computer whizz and the poker bet that made \$10bn [WWW document] http://technology.guardian.co.uk/ online/news/0,12597,1498367,00.html?gusrc $=$ rss(accessed 9th October 2006).

Reuters (2005). PartyPoker.com parent's stock surges after IPO [WWW document] http://www.msnbc.msn.com/id/8375090(accessed 9th October 2006).

Roy, A. (2005). Poker princes eye pot of gold - IIT alumni lord over company valued at $\$ 6$ billion [WWW document] http://www.telegraphindia.com/ 1050320/asp/frontpage/story_4515973.asp(accessed 9th October 2006).

Shapiro, C. and Varian, H.R. (1998). Information Rules: A Strategic Guide for the Network Economy, Boston: Harvard Business School Press.

Shulman, J.A. (2004). Mike Sexton: poker's premier ambassador [WWW document] http://www.cardplayer.com/poker_magazine/archives/ showarticle.php?a_id = 14279\&m_id =65546(accessed 9th October 2006).

Starluck Casino (1998). Welcome to Starluck Casino [WWW document] http://web.archive.org/web/19981212033031/www.starluck.com(accessed 9th October 2006).

Waller, M. (2005). City diary: not quite human [WWW document] http:// www.timesonline.co.uk/article/0,,630-1654149,00.html(accessed 9th October 2006).

Wild, D. and Day, K. (2005). PartyGaming: playing their cards right [WWW document] http://www.accountancyage.com/accountancyage/analysis/ 2138873/partygaming-playing-cards-right(accessed 9th October 2006).

\section{About the author}

Des Laffey is a lecturer in E-Commerce at Kent Business School, University of Kent. He received a B.A. in Economics and Politics from the University of Lancaster and an M.Sc. in Information Technology and Manufacture from the University of Hull. In his current role, he designed and set up an online Masters in E-Commerce, in collaboration with the Institute of Financial Services and major UK retail banks. His current research interests include online gambling, paid search and new ventures through ecommerce. 